\title{
Potential distribution of a climate sensitive species, the White-winged Snowfinch Montifringilla nivalis in Europe
}

MATTIA BRAMBILLA ${ }^{1,2,3 *}$ (D), JAIME RESANO-MAYOR ${ }^{4}$, RAPHAËL ARLETTAZ ${ }^{4}$ CHIARA BETTEGA ${ }^{5}$, ANAÏS BINGGELI ${ }^{4}$, GIUSEPPE BOGLIANI ${ }^{6}$, VERONIKA BRAUNISCH ${ }^{4,7}$, CLAUDIO CELADA ${ }^{1}$, DAN CHAMBERLAIN ${ }^{8}$, JULES CHIFFARD CARRICABURU ${ }^{9}$, MARIA DEL MAR DELGADO ${ }^{5}$, PHILIPPE FONTANILLES ${ }^{10}$, PRIMOŽ KMECL ${ }^{11}$, FRÄNZI KORNER $^{12}$, ROBERT LINDNER ${ }^{13}$, PAOLO PEDRINI ${ }^{2}$, JAKOB PÖHACKER ${ }^{14}$, BORUT RUBINIČ ${ }^{14}$, CHRISTIAN SCHANO ${ }^{12,15}$, DAVIDE SCRIDEL ${ }^{2,6}$, ELISEO STRINELLA ${ }^{16}$, NORBERT TEUFELBAUER ${ }^{17}$ and MIGUEL DE GABRIEL HERNANDO ${ }^{18,19}$

${ }^{1}$ LIPU/BirdLife Italia, Via Udine 3/A, I-43122, Parma, Italy.

${ }^{2}$ Museo delle Scienze, Sezione Zoologia dei Vertebrati, Corso del Lavoro e della Scienza 3, I-38123 Trento, Italy.

${ }^{3}$ Fondazione Lombardia per l'Ambiente, Settore biodiversità e aree protette, Largo 10 Luglio 1976 1, I-20822 Seveso (MB), Italy.

${ }^{4}$ University of Bern, Institute of Ecology and Evolution, Division of Conservation Biology, Baltzerstrasse 6, CH-3012 Bern, Switzerland.

${ }^{5}$ Department of Biology of Organisms and Systems and Biodiversity Research Unit, University of Oviedo, Oviedo, Spain.

${ }^{6}$ Dipartimento di Scienze della Terra e dell'Ambiente, Università degli Studi di Pavia, Via A. Ferrata 9, I-2720o Pavia, Italy.

${ }^{7}$ Forest Research Institute of Baden-Württemberg, Wonnhaldestrasse 4, D-791oo Freiburg, Germany.

${ }^{8}$ Dipartimento di Scienze della Vita e Biologia dei Sistemi, Università di Torino, Via Accademia Albertina 13, 10123 Turin, Italy.

${ }^{9}$ Ecole Pratique des Hautes Etudes (EPHE), PSL Research University, Centre d'Ecologie Fonctionnelle et Evolutive (CEFE), UMR 5175, CNRS, 1919 route de Mende, F-34293 Montpellier Cedex 5, France.

${ }^{10}$ Parc national des Pyrénées, Villa Fould, 2 rue du IV septembre, 65000 Tarbes, France.

${ }^{11}$ DOPPS BirdLife Slovenia, Tržaška cesta 2, SI-1ooo Ljubljana, Slovenia.

${ }^{12}$ Swiss Ornithological Institute, Seerose 1, CH - 6204 Sempach, Switzerland.

${ }^{13}$ Haus der Natur, Museum für Natur und Technik, Museumsplatz 5, A-502o Salzburg, Austria.

${ }^{14}$ Kurirska pot 27, SI-1360 Vrhnika, Slovenia.

${ }^{15}$ University of Zurich, Department of Evolutionary Biology and Environmental Studies, Winterthurerstrasse 190, CH - 8057 Zurich, Switzerland.

${ }^{16}$ Reparto Carabinieri Biodiversità, L'Aquila, Italy.

${ }^{17}$ BirdLife Austria, Wien, Austria.

${ }^{18}$ Grupo Ibérico de Anillamiento, Daoiz y Velarde 49 B, 24006 León, Spain.

${ }^{19}$ Department of Biodiversity and Environmental Management, Faculty of Biological and Environmental Sciences, Universidad de León, León, Spain.

*Author for correspondence; email: Brambilla.mattia@gmail.com

(Received 23 September 2019; revision accepted 04 January 2020) 


\section{Summary}

The White-winged Snowfinch Montifringilla nivalis nivalis is assumed to be highly threatened by climate change, but this high elevation species has been little studied and the current breeding distribution is accurately known only for a minor portion of its range. Here, we provide a detailed and spatially explicit identification of the potentially suitable breeding areas for the Snowfinch. We modelled suitable areas in Europe and compared them with the currently known distribution. We built a distribution model using 14,574 records obtained during the breeding period that integrated climatic, topographic and land-cover variables, working at a $2-\mathrm{km}$ spatial resolution with MaxEnt. The model performed well and was very robust; average annual temperature was the most important occurrence predictor (optimum between c. $-3^{\circ} \mathrm{C}$ and $o^{\circ}$; unsuitable conditions below $-10^{\circ}$ and above $5^{\circ}$ ). The current European breeding range estimated by BirdLife International was almost three times greater than that classified as potentially suitable by our model. Discrepancies between our model and the distribution estimated by BirdLife International were particularly evident in eastern Europe, where the species is poorly monitored. Southern populations are likely more isolated and at major risk because of global warming. These differences have important implications for the supposed national responsibility for conservation of the species and highlight the need for new investigations on the species in the eastern part of its European range.

Keywords: species distribution model, climate change, mountains

\section{Introduction}

Detailed knowledge of the occurrence and spatial arrangement of animal species and their preferred habitats is a basic, key requirement for most research applications and for species and habitat conservation. In this climate change era, climate-sensitive species (and environments) are of particular concern, as they are highly threatened by ongoing modifications in climatic parameters and by changes in the habitat prompted by such modifications.

The White-winged Snowfinch Montifringilla nivalis (hereafter, Snowfinch) in Europe (which includes the whole range of the nominate subspecies $M$. n. nivalis) inhabits a range restricted to higher elevations of central and southern mountain massifs, and is among the species most threatened by climate change on the continent (Brambilla et al. 2017a). Predicted changes in distribution and connectivity among suitable sites (Brambilla et al. 2017a), potential increase in the impact of human alteration to alpine habitats (Brambilla et al. 2016), modifications in snowcover and snow-melt date (Brambilla et al. 2018a, Resano-Mayor et al. 2019) and in foraging habitat (Brambilla et al. 2018b) suggest a very concerning status of the species, at least in the Alps, where the species has been most studied.

Despite the dramatic future prospects for the species, the Snowfinch had been little investigated until a few years ago and was classified as 'Least Concern' in the last Red List of European Birds (BirdLife International 2015). In recent years, evidence for range contractions and/or population declines has accumulated (Knaus et al. 2018, Scridel et al. 2017) and the Snowfinch is now regarded as a flagship species for high-elevation taxa and habitats threatened by climate change. The current breeding distribution of the species is reasonably well known only for the Alps, the Pyrenees and the Cantabrian Mountains, whereas for the Italian pre-Alps and Apennines, available data are less complete and accurate; in the Balkans, data are even scarcer and knowledge of the species' occurrence is still poor in several areas (see www.snowfinch.eu).

We aimed to identify those mountain areas in Europe with suitable habitats and climates for breeding Snowfinches and to compare them with the current estimated geographical range during the breeding season, in order to: i) provide a better understanding of the breeding distribution over the continent; ii) identify gaps in current knowledge by comparing our output with the currently 
known distribution as defined by BirdLife International (BirdLife International and Handbook of the Birds of the World, 2018; hereafter, "BirdLife distribution") and thus to pinpoint new, potentially important, areas to be explored (Bourg et al. 2005, Brambilla et al. 2009); and, iii) compare the potential importance for conservation of the different countries hosting Snowfinch populations according to current knowledge (BirdLife distribution relative to the breeding season) and to our model, respectively. All this information is essential to better understand distribution patterns for conservation-related purposes, such as identifying key areas and national responsibilities for Snowfinch conservation.

\section{Methods}

Data were collected as widely as possible throughout European countries, in the framework of different studies carried out by the authors (Brambilla et al. 2017b, 2018b, Resano-Mayor et al. 2017, 2019, Strinella et al. 2007) and by national parks and local institutions. All these data were collected in the form of spatially georeferenced observations. In addition, citizen science data (i.e. collected by the public) were gathered through online databases (www.ornitho.at, www. ornitho.ch, www.ornitho.it), after official requests specific to the purposes of the project (data downloaded and received in the period December 2018-April 2019). Data were therefore occurrence-only.

We collated all data for the period 1979-2018 and removed all records not satisfying the temporal and spatial requirements. We only kept records of breeding individuals (atlas code suggesting breeding or 'territorial' behaviour), or observed during the species' breeding season (15 May-31 July, i.e. the 'core period' of the breeding season, during which most individuals are likely to be involved in reproduction). All data recorded at a resolution coarser than $1-\mathrm{km}$ were discarded.

Overall, 14,574 records met the above criteria. Twenty-four observations were from elevations between 750 and 1,500 $\mathrm{m}$ asl, and 96 observations were recorded above 3,000 $\mathrm{m}$ (but below 3,700 $\mathrm{m})$. Most data $(14,454)$ were collected between 1,500 and 3,000 m (mean 2,247 $\pm 316 \mathrm{SD}$ ). Note that the recorded elevation (assigned based on the digital elevation model used for model building; see below) could be not exact, because of the resolution of the records (from one or a few meters, up to $1 \mathrm{~km}$ ); even an approximation of a very few hundreds of meters on mountain slopes may result in elevation differences of up to hundreds of metres because of the steep terrain.

To develop the distribution model, we considered climatic, topographic and land-use/land-cover variables. Climatic data were gathered by the CHELSA database for the period 1979-2013 (Karger et al. 2017) at a 30 arc seconds ( $\sim \mathrm{Imm})$ resolution. Topographic variables were derived from a $30-\mathrm{m}$ digital elevation model in GRASS GIS (Neteler et al. 2012). Land-cover data were derived from Corine Land Cover 2012 (European Environment Agency 2016). All environmental data were expressed at the scale of $2 \times 2 \mathrm{~km}$ cells, taking the average values for climatic predictors, slope and solar radiation, and the proportional cover for land-use/land-cover categories.

The same grid was used to process Snowfinch records and to create background points. All cells with one or more Snowfinch records were considered as occupied cells and used as occurrence cells for modelling (thus avoiding duplicates and reducing the number of records from the most intensively sampled areas). We thus obtained 2,473 independent $2 \times 2 \mathrm{~km}$ cells occupied by the species. The distribution of occurrence data and hence of occupied cells was not uniform over the European range. The Alps hosted the largest amount of data, followed by the Cantabrian Mountains. There were fewer data from the Pyrenees and the Apennines, but they were nonetheless adequately sampled (Figure $\mathrm{S}_{5}$ in the online supplementary material). Notably, environmental conditions in the Apennines were representative of Mediterranean mountains and this area may thus provide a test-site to check the model's ability to predict species distribution over the poorly sampled Mediterranean mountains.

The distribution model was developed using MaxEnt (hence, a presence-background method not requiring absence data), under the package ENMeval (Muscarella et al. 2014) in R (R Development 
Table 1. Variables selected in the final MaxEnt model and their relative effect, and other variables tested but not included. Irrespective of their inclusion, variables are subdivided into two groups (potentially important predictors vs. other variables). The number before the land-cover variables represents the CORINE category. A short description of the potential importance of the variables presumed to be potentially important for the species is also provided in the last column.

\begin{tabular}{|c|c|c|c|}
\hline Variable & Permutation importance & Effect & Potential importance \\
\hline \multicolumn{4}{|c|}{ Potentially important predictors of environmental suitability for Snowfinches } \\
\hline 23 - broad-leaved forest & 0.29 & negative & unsuitable habitat locally reaching high elevation \\
\hline $24-$ coniferous forest & 1.06 & negative & unsuitable habitat reaching high elevation \\
\hline 26 - natural grassland & 0.16 & positive & positive effect - important foraging habitat \\
\hline 31 - bare rocks & 0.25 & positive & positive effect - foraging and nesting habitat \\
\hline 32 - sparsely vegetated areas & 0.09 & positive & positive effect - potential foraging habitat \\
\hline annual average temperature & 94.27 & $\begin{array}{l}\text { quadratic (optimum between } \\
-3^{\circ} \text { and } \circ^{\circ} \mathrm{C} \text { ) }\end{array}$ & important driver of species occurrence \\
\hline precipitation of the warmest quarter & 1.88 & positive & $\begin{array}{l}\text { potential effect because of impact on vegetation } \\
\text { (e.g. seed production) }\end{array}$ \\
\hline slope & 2.01 & quadratic (optimum at c. $20^{\circ}$ ) & generally associated to slopes \\
\hline average solar radiation & & & important for microclimate \\
\hline precipitation of the coldest quarter & & & $\begin{array}{l}\text { potential positive effect (snow-cover in spring is } \\
\text { crucial for foraging) }\end{array}$ \\
\hline \multicolumn{4}{|c|}{$\begin{array}{l}\text { Other variables presumably less important - tested but not included in the models } \\
2 \text { - discontinuous urban fabric, } 3 \text { - industrial or commercial units, } 12-\text { non-irrigated arable land, } 13 \text { - permanently irrigated land, } 15-\text { vineyards, } 16-\text { fruit trees and berry } \\
\text { plantations, } 17 \text { - olive groves, } 18 \text { - pastures, } 20 \text { - complex cultivation patterns, } 21 \text { - land principally occupied by agriculture with significant areas of natural vegetation, } 22 \text { - } \\
\text { agro-forestry areas, } 25 \text { - mixed forest, } 27 \text { - moors and heathland, } 28 \text { - sclerophyllous vegetation, } 29-\text { transitional woodland-shrub, } 34-\text { glaciers and perpetual snow, } 35 \text { - } \\
\text { inland marshes, } 40 \text { - water courses, } 41 \text { - water bodies }\end{array}$} \\
\hline
\end{tabular}


Core Team 2016). 150,00o background cells were randomly identified within the most intensively sampled countries in the study region (irrespective of Snowfinch records), i.e. Portugal, Spain, France, Italy, Switzerland, Austria and Slovenia. All those countries harbour Snowfinch populations or are close to existing ones (Portugal) and hence potentially reachable by the species.

We used only the variables which did not lead to multicollinearity issues for modelling, on the basis of the generalized Variance-Inflation Factor (gVIF; Zuur et al. 2009), removing variables with values $>5$. Variables tested included those selected in the final model shown in Table 1 , in addition to other climatic and land cover variables. We tested climatic variables potentially relevant for Snowfinches as those related to temperature and snowfall regimes, and all land cover variables occurring within the study area, in three different combinations: i) only the variables of most importance for the species according to current knowledge, ii) the latter plus those more represented in mountain environments (i.e. the cover of pastures, mixed forest, moors and heathland, glaciers and permanent snow, water courses and water bodies), iii) all variables listed in Table 1 . Table $S_{I}$ in the online supplementary material contains further details about the potential effect of environmental variables.

We split occurrence data into four bins (using the function 'checkerboard 2'), i.e. in four partitions of spatially independent occurrence records, which were used for model training and validation over independent datasets. AUC (Area Under the Curve of the receiver operating characteristic-ROC-plot) and omission rates on test data (Muscarella et al. 2014) were considered (Table Si). Eight different values of the regularization multiplier were tested (from 0.5 to 4 with increments of 0.5), and the one leading to the model with the lowest AIC was selected. Then, the variables with the weakest effects (with permutation importance and percentage contribution both lower than I) were removed from the model, which was trained again with the eight different regularization multiplier values. This process was repeated until we obtained a final best-supported model. The logistic model output was reclassified into three different suitability categories to facilitate interpretation: unsuitable (lower than maximum training sensitivity plus specificity threshold), partly suitable (between maximum training sensitivity plus specificity threshold and $10^{\text {th }}$ percentile), and definitely suitable (higher than $10^{\text {th }}$ percentile). These two thresholds are those generally adopted for binary reclassification of models produced using MaxEnt (Liu et al. 2005, 2013, Engler et al. 2014).

To refine the predictions at a finer scale in order to provide outputs as precise as possible, we limited the potential occurrence of suitable sites to the region-specific elevation belt inhabited by the species, by filtering out as unsuitable all areas below $1,500 \mathrm{~m}$ (this being a conservative value, selected to exclude areas at elevations where Snowfinches had never been found in recent years in Europe). The changes due to this post-modelling correction were almost imperceptible at the working scale (see Figure $\mathrm{S}_{1}$ ).

Finally, we performed a country-based comparison of the suitable breeding area as predicted by our model, with that estimated to be occupied by breeding Snowfinches according to the BirdLife distribution, the most widely used and comprehensive estimation of the species' geographic range currently available. Similarly, we compared the estimated percentage of the species' European range within each country based on our models and the BirdLife distribution. These assessments are particularly relevant because the percentage of a species' population within a country (likely correlated with the percentage of range within it) is among the criteria used to define a country's responsibility for the conservation of a given species (BirdLife International 2017). This analysis was performed i) using raster data and the relative approximation (resulting in an irrelevant difference over such a broad scale), and ii) without any correction for elevation. In addition, the analysis was restricted to the countries hosting the species as a breeder according to the BirdLife distribution, and to those closely neighbouring Snowfinch populations in other countries (Andorra and Bulgaria).

\section{Results}

The output of the distribution model was identical for the three sets of variables tested. The most supported MaxEnt distribution model performed well and was very robust, displaying the same 


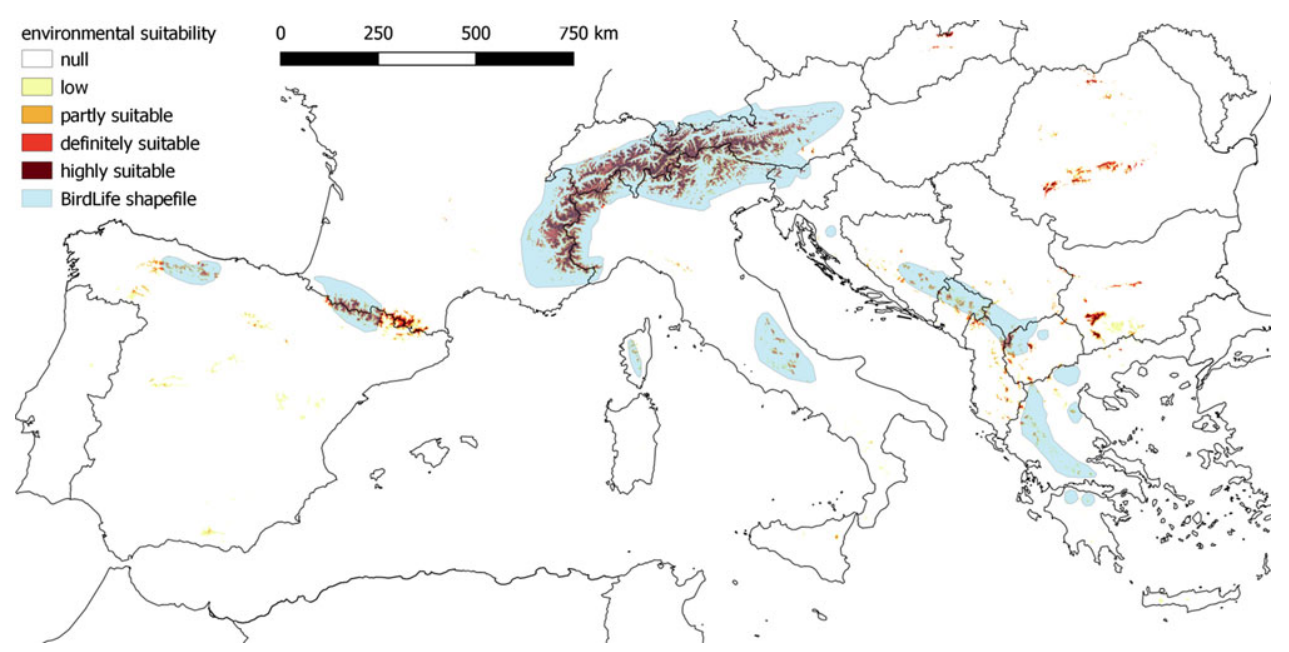

Figure 1. Modelled (our work) and reported (BirdLife) distribution of White-winged Snowfinch in Europe. Partly suitable sites are those with suitability above the maximum training sensitivity plus specificity threshold, definitely suitable sites those higher than the $10^{\text {th }}$ percentile (see text for further details); highly suitable areas are those with suitability close to the maximum value. Areas below $1,500 \mathrm{~m}$ were considered as unsuitable (see also Figure $\mathrm{S}_{1}$ ).

AUC and omission rates very close to the expected values, over all the four independent bins (Table Si).

Average annual temperature (bioI) was by far the most important predictor of species occurrence, having the only notable effect according to permutation importance; it had a quadratic effect, with an optimum for Snowfinch occurrence between c. $-3^{\circ} \mathrm{C}$ and $o^{\circ}$, and unsuitable conditions below $-10^{\circ}$ and, especially, above $4^{\circ}-5^{\circ}$. The other climatic predictor included in the final model was precipitation of the warmest quarter (bio18); this variable was slightly positively correlated with environmental suitability for Snowfinches, as were natural grassland, bare rocks and sparsely vegetated areas. Forest cover (both broadleaved and coniferous) had a negative effect on environmental suitability, whereas a quadratic relationship was identified between suitability and slope, with a peak at intermediate slope values (Table 1 ). The effect of environmental variables on habitat suitability for Snowfinches is shown in Figure $\mathrm{S}_{4}$.

Modelled and reported (BirdLife) distributions were generally similar (Figure 1 ), although there were some important discrepancies (Figures $\mathrm{S}_{2}-\mathrm{S}_{3}$ ). Similarly, the estimated suitable area per country displayed important differences; in general, the area inhabited by Snowfinches according to the BirdLife distribution was greater $\left(249,221 \mathrm{~km}^{2}\right)$ than the area suitable or potentially suitable estimated by our model $\left(91,044 \mathrm{~km}^{2}\right)$. The percentages of the European species' range hosted by each country calculated according to the model and the BirdLife distribution were significantly correlated (Spearman's rho $0.71, P=0.001$ ), but revealed some important discrepancies in the relative relevance of each national population (Table 2 ).

\section{Discussion}

For a species so highly threatened by climate change (Brambilla et al. 2018b, Resano-Mayor et al. 2019), it is essential to accurately define current and potential distribution in order to plan conservation strategies and implement measures in relevant sites; distribution modelling may help considerably in that sense (Engler et al. 2017). Our study provides a detailed and spatially explicit identification of the potentially suitable breeding areas of the nominate Snowfinch 
Table 2. Comparison between suitable area and relative distribution share per country according to our distribution model and the BirdLife distribution, respectively. Country extent mirrors the raster resolution of the distribution model. List of abbreviations used in the table: pot_suit: area potentially suitable; def_suit: area definitely suitable; tot_suit: sum of potentially and definitely suitable area; area_BLD: extent of BirdLife distribution within the country; \%_suit_model: percentage extent of the country potentially or definitely suitable; \%_BLD: percentage extent of the country occupied by the species according to BirdLife distribution; \%_species_model: percentage of Snowfinch European range within the country according to the potentially or definitely suitable areas (considering only the countries listed in the table); \%_species_BLD: percentage of Snowfinch range within the country according to BirdLife distribution

\begin{tabular}{|c|c|c|c|c|c|c|c|c|c|}
\hline \multirow[b]{2}{*}{ Country } & \multirow[b]{2}{*}{ country extent } & \multicolumn{3}{|c|}{ Model } & \multirow{2}{*}{$\frac{\text { BL distr }}{\text { area_BLD }}$} & \multicolumn{2}{|c|}{ National scale } & \multicolumn{2}{|c|}{ European range } \\
\hline & & pot_suit & def_suit & tot_suit & & $\begin{array}{c}\% \text { osuit__ } \\
\text { model }\end{array}$ & $\%$ \%_BLD & \%_species_model & \%_species_BLD \\
\hline France & 549264 & 4892 & 9860 & 14752 & $44073 \cdot 4$ & 2.7 & 8.0 & 16.2 & $17 \cdot 7$ \\
\hline Spain & 498684 & 3208 & 2696 & 5904 & 12692.2 & 1.2 & 2.5 & 6.5 & 5.1 \\
\hline Italy & 301152 & 7648 & 12988 & 20636 & 64509.8 & 6.9 & 21.4 & 22.7 & $25 \cdot 9$ \\
\hline Germany & 357578 & 1084 & 508 & 1592 & 6088.7 & 0.4 & 1.7 & 1.7 & 2.4 \\
\hline Greece & 132184 & 736 & 204 & 940 & 20977.2 & 0.7 & 15.9 & 1.0 & 8.4 \\
\hline Bulgaria & 111036 & 1212 & 1120 & 2332 & 0.0 & 2.1 & 0.0 & 2.6 & 0.0 \\
\hline Serbia & 88456 & 968 & 380 & 1348 & 5864.8 & 1.5 & 6.6 & 1.5 & 2.4 \\
\hline Austria & 83808 & 7604 & 12436 & 20040 & 45910.0 & $23 \cdot 9$ & 54.8 & 22.0 & 18.4 \\
\hline Croatia & 56488 & 88 & 8 & 96 & 622.3 & 0.2 & 1.1 & 0.1 & 0.2 \\
\hline Bosnia and Herzegovina & 51196 & 1104 & 224 & 1328 & 6899.1 & 2.6 & 13.5 & 1.5 & 2.8 \\
\hline Switzerland & 41320 & 4084 & 11980 & 16064 & 23795.0 & 38.9 & 57.6 & 17.6 & $9 \cdot 5$ \\
\hline Albania & 28488 & 940 & 472 & 1412 & 1618.4 & 5.0 & $5 \cdot 7$ & 1.6 & 0.6 \\
\hline Macedonia & 25396 & 924 & 736 & 1660 & 4641.7 & 6.5 & 18.3 & 1.8 & 1.9 \\
\hline Slovenia & 20248 & 516 & 364 & 880 & 4146.5 & $4 \cdot 3$ & 20.5 & 1.0 & 1.7 \\
\hline Montenegro & 13872 & 1280 & 348 & 1628 & 7218.0 & 11.7 & 52.0 & 1.8 & 2.9 \\
\hline Andorra & 460 & 120 & 264 & 384 & 0.0 & 83.5 & 0.0 & 0.4 & 0.0 \\
\hline Lichtenstein & 160 & 24 & 24 & 48 & 160.0 & 30.0 & 100.0 & 0.1 & 0.1 \\
\hline
\end{tabular}


subspecies Montifringilla nivalis nivalis, which inhabits European mountains. Analyses confirmed the primary importance of climatic (in particular temperature) and topographic (slope) parameters in determining environmental suitability and hence distribution in Snowfinches (see Table $I$ and Figure $\mathrm{S}_{5}$ ), in concordance with assessments carried out over finer spatial scales (Brambilla et al. 2016, 2017a). As expected, environmental suitability for Snowfinches increases with the cover of natural grassland and sparsely vegetated areas, which provide key foraging habitats (Brambilla et al. 2017b, 2018), and with bare rocks, which provide potential nesting sites.

Snowfinch occurrence data mostly came from the Alps, where the species has a rather broad distribution; however, the model correctly predicted occurrence in other, more isolated mountain chains, such as the Cantabrian Mountains and the Apennines. The latter served as a test-site for model performance in the Mediterranean region; these results were encouraging, as the predicted distribution represented well the actual occurrence of the species, including some isolated habitat patches irregularly occupied by the species which were classified as potentially suitable by the model (E. Strinella and M. Brambilla pers. obs.). Despite this, we cannot exclude the possibility that the potential region-specific variations in habitat associations could to some extent affect model predictions for poorly sampled areas, such as the Balkans. Further occurrence data should be collected in south-eastern Europe to exclude such potential limitations, as well as to improve knowledge and model accuracy for this relatively poorly known portion of the European range of the species. Nevertheless, we believe that the predicted suitability i) makes sense also for southeastern Europe (see below and supplementary material), and ii) can be used to highlight areas requiring further investigation.

In southern European mountains, the availability of potentially suitable areas according to the model is much more restricted and fragmented than the overall species range suggested by the BirdLife distribution, and Snowfinches likely occupy smaller, and more isolated, suitable patches there (Figure I), in areas characterised by higher average temperatures. As a consequence, populations breeding in these mountains (Cantabrian Mountains, Apennines, Balkans) appear to be at greater risk because of climate change impacts. Future studies based on the comparison of the species' autecology and demography between large suitable areas (e.g. Alps, Pyrenees) and smaller, more marginal ones (e.g. Cantabrian Mountains, Apennines, Corsica, several areas in the Balkans) may help to understand the potential impacts of climate change by allowing the inclusion of large gradients of climate and isolation.

Despite a general concordance with the currently known distribution, modelling also highlighted some important differences with the current range of the species as defined by BirdLife International (BirdLife International and Handbook of the Birds of the World 2018), especially (but not exclusively) for eastern Europe. Generally, the BirdLife distribution includes most of the areas predicted to be suitable by our model (apart for some parts of the Cantabrian Mountains and Pyrenees), but also includes rather large unsuitable areas compared to our models. Some of these discrepancies are likely due to the different spatial resolution of the two approaches; approximate polygons surrounding occupied areas and not considering elevation are very likely to 'overpredict' occurrence compared to a dedicated species distribution model for such a species strongly linked to high elevation. Nevertheless, some discrepancies definitely require further investigation (see Figures $\mathrm{S}_{2}-\mathrm{S}_{3}$ for detailed comments and comparisons). Some of the differences arose because the model identified potentially suitable sites in mountain chains currently believed not to harbour breeding Snowfinches, such as the Carpathians, Rila and Rhodope mountains, and Mount Etna. In some of these sites, further investigations should be carried out (see below and supplementary material for further discussion). Suitable areas in the Balkans show only a moderate concordance with the Snowfinch range according to the BirdLife distribution (Figure S2). Even if this is largely attributable to the relatively low spatial resolution of the BirdLife distribution, which needs to be considered at a larger scale, most areas encompassed by it in Greece are located below 1,500 m, and suitable areas are located largely outside the supposed species range. In Albania, Macedonia and Bulgaria, several suitable patches occur outside the known range of the species. Some of those sites could potentially host important populations that need to be preserved for the conservation of the 
species in eastern Europe. According to the BirdLife distribution, Snowfinches do not breed in Bulgaria. However, our model suggested the availability of large suitable patches in the southwestern part of the country. Even if the species is currently considered as non-breeding in the country, historical records of breeding pairs in the 1960s were reported (although regarded as not reliable) for Mt. Rila (Ivanov 2011). According to our model, this site has the highest suitability in the country. Further intensive field work is needed in this key unknown area.

These differences have important implications for the supposed national responsibility for the species' conservation, and such discrepancies result also in very large differences in the expected frequency of a species within a country (Table 2). For example, the estimated area occupied by Snowfinch in Greece according to the BirdLife distribution is 22 times higher than the suitable/ potentially suitable area estimated by our model. Considering the BirdLife distribution, Greece should host a proportion of the European Snowfinch breeding range that is very close to that harboured by Switzerland, whereas our model suggests that the proportion of the European Snowfinch range in Switzerland is almost 18 times that found in Greece. A further example relevant to those regarding the perceived frequency of the species within each country is provided by Montenegro, where Snowfinches should occur in more than half of the country according to the BirdLife distribution, whereas our model suggests that less than $12 \%$ of the country is potentially suitable for the species, and only $2.5 \%$ is definitely suitable.

The concerning situation of the species in Europe has triggered several studies on its ecology, distribution and demography in several areas in Europe, namely the Cantabrian Mountains, the Pyrenees, Corsica, the Alps and the Apennines (see ongoing initiatives on www.snowfinch.eu). Unfortunately, we are not aware of any detailed study in the Balkans. The results of our work suggest the need for new investigations on the species in the eastern portion of its European range, where the basic distribution of the species is also poorly known. In addition, such areas need to be investigated in the future, as they could provide key features for planning conservation measures for this species. Within such sites, Snowfinches may experience climatic conditions that are now lacking in other European mountains, but that will be potentially much more widespread in the future. In addition, an increase in the availability of occurrence data from the Balkans could confirm or increase the accuracy of model predictions for this area. Further site-specific studies to better understand the ecology and population dynamics of the species are required across the entire geographic range to better assess Snowfinch conservation status and promote management and other conservation actions for the most emblematic (and highly threatened) alpine passerine of Europe.

\section{Supplementary Materials}

To view supplementary material for this article, please visit http://dx.doi.org/I0.1017/ So959270920000027.

\section{Acknowledgements}

We are very grateful to National/Natural Parks in France, Italy and Spain (Ecrins, Vanoise, Mercantour, Pyrenees, Stelvio, Paneveggio-Pale di San Martino, Picos de Europa), to Haus der Natur, M. Jovičević, D. Uzunova, and to the several volunteers who uploaded their Snowfinch observations on ornitho websites, park databases and the database of DOPPS BirdLife Slovenia, for help with data collection. We thank H. Schmid, R. Lardelli, D. Rubolini and the management group of ornitho.it, ornitho.at and ornitho.ch for helpful collaboration. We are also very grateful to B. Nikolov, K. Mikulic, the Associate Editor G. Buchanan and an anonymous reviewer for helpful comments. Stelvio National Park and Paneveggio-Pale di San Martino Natural Park also provided logistic facilities. We are grateful to M. Anderle, A.G. Barras, M. Bazzanella, J. Besimo, F. Capelli, M. Cortesi, N. Horrenberger, E. Jiménez, C. Jourdan, M. Maldonado, G. Masiero, V. Moser, B. Sangalli and S. Vignali who helped with fieldwork in the Alps. MB and CC were partly supported 
by the project Mediterranean Mosaics II funded by MAVA to Lipu. MD was supported by the Spanish Ministry of Sciences, Innovation and Universities (\#CGL2016-79764-P) and by a Spanish Ramon y Cajal grant RYC-2014-16263.

\section{References}

BirdLife International (2017) European birds of conservation concern: populations, trends and national responsibilities. Cambridge, UK: BirdLife International.

BirdLife International (2015) European Red List of Birds. Luxembourg: Office for Official Publications of the European Communities.

BirdLife International and Handbook of the Birds of the World (2018) Bird species distribution maps of the world. Version 2018.1.

Bourg, N. A., McShea, W. J., Gill and D. E. (2005) Putting a CART before the search: Successful habitat prediction for a rare forest herb. Ecology 86: 2793-2804.

Brambilla, M., Capelli, F., Anderle, M., Forti, A., Bazzanella, M., Masiero, G., Bogliani, G., Partel, P., Pedrini, P., Pedrotti, L. and Scridel, D. (2018a) Landscape-associated differences in fine-scale habitat selection modulate the potential impact of climate change on White-winged Snowfinch Montifringilla nivalis. Bird Study 65: 525-532.

Brambilla, M., Caprio, E., Assandri, G., Scridel, D., Bassi, E., Bionda, R., Celada, C., Falco, R., Bogliani, G., Pedrini, P., Rolando, A. and Chamberlain, D. (2017a) A spatially explicit definition of conservation priorities according to population resistance and resilience, species importance and level of threat in a changing climate. Divers. Distrib. 23: 727-738.

Brambilla, M., Casale, F., Bergero, V., Crovetto, G. M., Falco, R., Negri, I., Siccardi, P. and Bogliani, G. (2009) GIS-models work well, but are not enough: Habitat preferences of Lanius collurio at multiple levels and conservation implications. Biol. Conserv. 142: 2033-2042.

Brambilla, M., Cortesi, M., Capelli, F., Chamberlain, D., Pedrini, P. and Rubolini, D. (2017b) Foraging habitat selection by Alpine White-winged Snowfinches Montifringilla nivalis during the nestling rearing period. J. Ornithol 158: 277-286.
Brambilla, M., Pedrini, P., Rolando, A. and Chamberlain, D. E. (2016) Climate change will increase the potential conflict between skiing and high-elevation bird species in the Alps. J. Biogeogr 43: 2299-2309.

Brambilla, M., Resano-Mayor, J., Scridel, D., Anderle, M., Bogliani, G., Braunisch, V., Capelli, F., Cortesi, M., Horrenberger, N., Pedrini, P., Sangalli, B., Chamberlain, D., Arlettaz, R. and Rubolini, D. (2018b) Past and future impact of climate change on foraging habitat suitability in a high-alpine bird species: Management options to buffer against global warming effects. Biol. Conserv. 221: 209-218.

Engler, J. O., Rödder, D., Stiels, D. and Förschler, M. I. (2014) Suitable, reachable but not colonised: seasonal niche duality in an endemic mountainous songbird. J. Ornithol 155: 657-669.

Engler, J. O., Stiels, D., Schidelko, K., Strubbe, D., Quillfeldt, P. and Brambilla, M. (2017) Avian SDMs: current state, challenges, and opportunities. J. Avian Biol 48: 1483-1504.

European Environment Agency (2016) Corine Land Cover 2012 [WWW Document]. https://www.eea.europa.eu/data-and-maps/ data/external/corine-land-cover-20I2. URL https://www.eea.europa.eu/data-and-maps/ data/external/corine-land-cover-2012

Ivanov, B. (2011) The Fauna of Bulgaria. Vol. 30. Aves. Part III. Sofia: Prof. Marin Drinov Publ. House.

Karger, D. N., Conrad, O., Böhner, J., Kawohl, T., Kreft, H., Soria-Auza, R. W., Zimmermann, N. E., Linder, H. P. and Kessler, M. (2017) Climatologies at high resolution for the earth's land surface areas. Sci. Data 4: 170122.

Knaus, P., Antoniazza, S., Wechsler, S., Guélat, J., Kéry, M., Strebel, N. and Sattler, T. (2018) Swiss Breeding Bird Atlas 2013-2016. Distribution and population trends of birds in Switzerland and Liechtenstein. Sempach: 
Swiss Ornithological Institute, Schweizerische Vogelwarte.

Liu, C., Berry, P. M., Dawson, T. P. and Person, R. G. (2005) Selecting Thresholds of occurrence in the predictions of species distribution. Ecography 28: 385-393.

Liu, C., White, M. and Newell, G. (2013) Selecting thresholds for the prediction of species occurrence with presence-only data. J. Biogeogr 40: 778-789.

Muscarella, R., Galante, P. J., Soley-Guardia, M., Boria, R.A., Kass, J. M., Uriarte, M. and Anderson, R. P. (2014) ENMeval: An R package for conducting spatially independent evaluations and estimating optimal model complexity for Maxent ecological niche models. Methods Ecol. Evol. 5: 1198-1205.

Neteler, M., Bowman, M. H., Landa, M. and Metz, M. (2012) GRASS GIS: A multipurpose open source GIS. Environ. Model. Softw. 31: 124-130.

R Development Core Team (2016) R: A Language and Environment for Statistical Computing. Vienna, Austria: R Foundation for Statistical Computing.

Resano-Mayor, J., Fernández-Martín, Á., Hernández-Gómez, S., Toranzo, I., España, A., Gil, J. A., de Gabriel, M., Roa-Álvarez, I., Strinella, E., Hobson, K. A., Heckel, G. and
Arlettaz, R. (2017) Integrating genetic and stable isotope analyses to infer the population structure of the White-winged Snowfinch Montifringilla nivalis in Western Europe. J. Ornithol. 158: 395-405.

Resano-Mayor, J., Korner-Nievergelt, F., Vignali, S., Horrenberger, N., Barras, A. G., Braunisch, V., Pernollet, C. A. and Arlettaz, R. (2019) Snow cover phenology is the main driver of foraging habitat selection for a high-alpine passerine during breeding: implications for species persistence in the face of climate change. Biodivers. Conserv. 1-17.

Scridel, D., Bogliani, G., Pedrini, P., Iemma, A., Von Hardenberg, A. and Brambilla, M. (2017) Thermal niche predicts recent changes in range size for bird species. Clim. Res. 73: 207-216.

Strinella, E., Ricci, F. and Vianale, P. (2007) Uso dell'habitat nel Fringuello alpino (Montifringilla nivalis) in periodo riproduttivo in un'area sub-antropizzata: Campo Imperatore (Gran Sasso-Abruzzo). Alula 14: 107-114.

Zuur, A. F., Ieno, E. N., Walker, N., Saveliev, A. A. and Smith, G. M. (2009) Mixed effects models and extensions in ecology with $R$, Statistics for Biology and Health. New York: Springer New York. 